\title{
Expression of Arthritis-causing HLA-B27 on Hela Cells Promotes Induction of c-fos in Response to In Vitro Invasion by Salmonella typhimurium
}

\author{
Takashi Ikawa, ${ }^{\star}$ Makoto Ikeda, ${ }^{*}$ Akihiro Yamaguchi, ${ }^{*}$ Wen Chan Tsai, ${ }^{*}$ Naoto Tamura, ${ }^{*}$ Noriyuki Seta, ${ }^{*}$ Mary Trucksess, ${ }^{\ddagger}$ \\ Richard B. Raybourne,$^{\S}$ and David Tak Yan Yu* \\ *Rheumatology Division, UCLA School of Medicine, Los Angeles, California 90095-167022; ${ }^{\ddagger}$ Center for Food Safety and Applied \\ Nutrition, Food and Drug Administration, Washington, D.C. 20204; and ${ }^{\S}$ Immunobiology Branch, Food and Drug Administration, \\ Laurel, Maryland 20708
}

\begin{abstract}
HLA-B27 confers a very strong genetic predisposition to development of a reactive arthritis after infection by bacteria such as Salmonella typhimurium. This study examines the role of HLA-B27 in the initiation of the earliest host activities after exposure to Salmonella, namely activation of the immediate early genes in the epithelial cells. Our major finding is that in Hela cells, the expression of c-fos was induced by Salmonella invasion only when the cells expressed the transfected HLA-B27 gene, but not the HLA-A1 gene or a truncated HLA-B27 gene lacking the exons encoding the cytoplasmic domain. C-fos is potentially capable of complexing with members of the c-jun family to become the AP-1 transcription complex. Parallel to c-fos expression, we found that only with the HLA-B27 transfectant was there expression of AP-1. AP-1 potentially controls the expression of a large number of genes. On screening a panel of proinflammatory molecules, we found that Salmonella invasion induced expression of monocyte chemoattractant protein-1 in the HLA-B27 cells. Since each of these separate positive findings belong to the same cascade of events after cell activation, together they reinforce the hypothesis that HLA-B27 plays a modulatory role in the early signal transduction events induced by Salmonella invasion. This hypothesis adds another item to the list of allele-specific activities carried out by HLA class I molecules. If similar activation also occurs in the joints, it may play a major role in arthritis. (J. Clin. Invest. 1998. 101:263-272.) Key words: HLA-B27 • reactive arthritis • c-fos • AP-1 • MCP-1
\end{abstract}

\section{Introduction}

Although Salmonella-induced reactive arthritis is initiated by an episode of Salmonella typhimurium gastrointestinal infection, no viable pathogen has been recovered from the joints (1). Importantly, the majority of the patients carry the HLA

The first three authors contributed equally to the project.

Address correspondence to Dr. David Yu, 35-40 Rehabilitation Center, Rheumatology Division, UCLA, 1000 Veteran Ave., Los Angeles, CA 90095-167022. Phone: 310-825-5047; FAX: 310-206-8606; E-mail: dyu@med1.medsch.ucla.edu or dtyyu@ucla.edu

Received for publication 23 April 1997 and accepted in revised form 29 October 1997.

The Journal of Clinical Investigation

Volume 101, Number 1, January 1998, 263-272

http://www.jci.org class I allele, HLA-B27 (2). Based on studies of family cohorts and HLA-B27 transgenic animals, it is accepted that HLA-B27 is one of the arthritis-causing genes $(3,4)$. The once-prevailing hypothesis that HLA-B27 induces arthritis by presenting Salmonella-derived peptides to $\mathrm{CD} 8+\mathrm{T}$ lymphocytes has been supported only by circumstantial evidence (5). The now equally appealing hypothesis postulates that HLA-B27 causes disease by altering the susceptibility of host cells, either to bacterial invasion or to bacterial multiplication $(6,7)$. However, supporting experimental results are reportedly not reproducible (8). This hypothesis would be the case if Salmonella invasion initiates several interconnecting molecular cascades of cellular reaction, and the reported observations reflect very late events. What is needed, then, is to focus on the earlier molecular processes.

In this paper, we focus on two such processes. The first is the expression of c-fos, a rapid response immediate-early gene. The second process we measure is generation of proinflammatory cytokines and chemokines. The c-fos is selected because it is the point of convergence of multiple signal transduction pathways (9), so that measuring such a parameter will allow simultaneous assessment of diverse pathways.

To study the role of HLA-B27, we transfected HLA-B27 and the arthritis-unrelated HLA-A1 into Hela cells (10). Since the cytoplasmic domain of the HLA class I molecules carries a serine residue that can potentially participate in signal transduction events, we also generated a truncated mutant of the HLA-B27. We found that expression of the parent HLA-B27 gene modulated the response of the cells to Salmonella invasion to promote the expression of c-fos gene, and also to generate monocyte chemoattractant protein-1 (MCP-1).

From these findings, we hypothesize that expression of HLA-B27 is associated with the potential of activating otherwise silent signal transduction pathways. Depending on the location in the hosts and whether the cytokines or chemokines activated are proinflammatory, this HLA-B27-associated activation can contribute to the development of joint inflammation.

\section{Methods}

Construction of the cDNA of an HLA-B27 mutant lacking the sixth and seventh exons. This cDNA was constructed by PCR using the cDNA of B*2705 as template and the Pfu DNA polymerase as enzyme (Stratagene Inc., La Jolla, CA). The 5' primer was 5'-CGAAGTCGACATGCG GGTCACGGCG-3', which consisted of the

1. Abbreviations used in this paper: EMSA, electrophoretic mobility shift assay; MCP-1, monocyte chemoattractant protein-1; RT, reverse transcription; SIE, sis-inducible enhancer; SRE, serum response element; TCF, ternary complex factor. 
Sall site and the first 15 bases of exon 1 of $B * 2705$. The $3^{\prime}$ primer was 5'-GGAAGAGCTCAGTGAGGATCCTCA-3', which consisted of the BamH1 site and the terminal 15 bases of exon 5 of $\mathrm{B} * 2705$. The PCR procedures followed those reported previously (11). This PCR product was purified by the QIAquick PCR purification kit (QIAGEN Inc., Chatsworth, CA), and then cloned into the RSV5.neo vector using its unique SalI and BamHI sites. The correctness of the sequence was verified by the Sequenase 2.0 DNA sequencing kit (Amersham Corp., Arlington Heights, IL). This gene was designated as the "mutant B27".

Cell lines and culture condition. The Hela cell line was purchased from American Type Culture Collection (Rockville, MD). We obtained the cDNA encoding the $\mathrm{B} * 2705$ gene and the HLA-A1 gene from Dr. B. Carreno (University of Washington, Seattle, WA) and Dr. R. Turner (National Institutes of Health, Bethesda, MD) respectively. The genes have already been inserted into the RSV5.neo vector by the respective investigators. These as well as the mutant B27 were transfected into the Hela cells using Lipofectin and following a protocol provided by the manufacturer (GIBCO BRL, Gaithersburg, MD). G418-resistant cell colonies were screened by immunofluorescence for the expression of HLA-B27 and HLA-A1. These transfectants were designated as the "B27-Hela," the "A1-Hela" and the "mutant B27-Hela." Cells were cultured in RPMI with $10 \%$ fetal calf sera at $37^{\circ} \mathrm{C}$ in $5 \% \mathrm{CO}_{2}$. Media for the transfectants were supplemented with $0.5 \mathrm{mg} / \mathrm{ml} \mathrm{G} 418$.

Monoclonal antibodies. The IgG monoclonal antibodies used were the W6/32, the ME1, and the GS 142.2. The W6/32 and the ME1 were purchased from American Type Culture Collection. The GS142.2 was kindly provided by Dr. I. Hellström (Bristol-Meyers Squibb Pharmaceuticals, Seattle, WA). The W6/32 is reactive with HLA class $I$ of the $-\mathrm{A},-\mathrm{B}$, and $-\mathrm{C}$ series. The ME1 is reactive with the following HLA-B alleles: B7, B22, B27, B42, B67, and B73. The GS142.2 is reactive with HLA-A1 and HLA-Aw36. Flow cytometric analysis used PE-conjugated goat anti-mouse IgG as the second antibody. Details of the method have been reported previously (11).

Immunoprecipitation of HLA-B27. Cells were first cultured for $45 \mathrm{~min}$ in methionine and cysteine-free RPMI medium containing $10 \%$ dialyzed fetal calf sera. Samples of $5 \times 10^{6}$ cells were then labeled for $4 \mathrm{~h}$ with $0.1-0.2 \mathrm{mCi}$ of $\left[{ }^{35} \mathrm{~S}\right]$ methionine and $\left[{ }^{35} \mathrm{~S}\right]$ cysteine (DuPont-NEN, Boston, MA). The cells were lysed on ice for $30 \mathrm{~min}$ with $0.5 \%$ NP-40, $20 \mathrm{mM}$ PMSF, $5 \mathrm{mM}$ iodoacetamide in $100 \mathrm{mM}$ $\mathrm{NaCl}$, and $10 \mathrm{mM}$ Tris $\mathrm{HCl}, \mathrm{pH}$ 7.4. Lysates were precleared overnight at $4^{\circ} \mathrm{C}$ with $50 \mu \mathrm{l}$ of a $10 \%$ suspension of Pansorbin (Calbiochem Corp., San Diego, CA). Precleared samples were immunoprecipitated with ME1 antibody conjugated to protein A-agarose (Santa Cruz Biotechnology, Santa Cruz, CA). Immunoprecipitates were eluted with $2 \%$ SDS sample buffer at boiling water temperature, and the molecules were then separated by SDS-PAGE in a $10.5 \%$ polyacrylamide gel. The gels were exposed to X-ray film overnight before development.

Bacterial strains and invasion procedure. The following bacterial strains were kindly provided by Dr. B. Finlay (University of British Columbia, Vancouver, Canada): wild-type Salmonella typhimurium SL1344, the noninvasive mutant SB111, and the SB111 carrying the inv gene of Yersinia pseudotuberculosis (12). Unless otherwise stated, the wild-type Salmonella strain will be referred to in this paper as Salmonella. An inoculum of one of these bacterial strains into a 5-ml aliquot of Luria broth was cultured overnight at $37^{\circ} \mathrm{C}$ without shaking the culture flask. Hela, B27-Hela, mutant B27-Hela, or A1-Hela cells were seeded at a density of $5 \times 10^{6}$ cells per 100 -mm diameter culture plate, or $1-2 \times 10^{5}$ cells per well of a 24 -well culture plate. The next day, Salmonella were added to achieve a bacterium/cell ratio of 25:1. The preparations were then cultured at $37^{\circ} \mathrm{C}$. In a small number of experiments, culture was terminated after $30 \mathrm{~min}$. In the rest, culture was maintained for $1 \mathrm{~h}$. Afterwards, the Hela cells were washed four times with PBS containing $50 \mu \mathrm{g} / \mathrm{ml}$ of gentamicin sulfate, and then incubated in RPMI 10\% FCS containing $100 \mu \mathrm{g} / \mathrm{ml}$ gentamicin sulfate. Control mock-invaded samples were those washed in parallel, except that no bacteria were added. To enumerate the number of bacteria associated with the cells, at various time points after initiation of culture the culture wells were washed $4 \times$ with PBS. $1 \mathrm{ml}$ of $1 \%$ Triton X-100 was added to each well to lyse the cells. This bacterial sample was then plated onto tryptic soy agar plates and cultured for $24 \mathrm{~h}$ at $37^{\circ} \mathrm{C}$ before counting the number of colonies.

Extraction of RNA, reverse transcription, and adjustment of sample concentration for the reverse transcription $(R T)-P C R$ assay. Total RNA was extracted from cells by the guanidium thiocyanate MicroRNA isolation kit following a protocol provided by the manufacturer (Stratagene Inc.). The concentration of RNA was assessed by a GenQuant II spectrophotometer (Pharmacia LKB Biotechnology Inc., Piscataway, NJ). Reverse transcription was carried out in $20-\mu \mathrm{l}$ reaction volumes. Besides $1 \mu \mathrm{g}$ of RNA, each sample contained the following: $200 \mathrm{U}$ Moloney murine leukemia virus reverse transcriptase (GIBCO BRL), 20 U RNase inhibitor (Promega Corp., Madison, WI), $2 \mu \mathrm{l}$ of $10 \times$ PCR Buffer II (Perkin Elmer Corp., Foster City, CA), $5 \mathrm{mM} \mathrm{MgCl}_{2}, 0.5 \mu \mathrm{g}$ Oligo(dT) ${ }_{15}$ (Promega Corp.), and $0.5 \mathrm{mM}$ each of dATP, dCTP, dGTP, and dTTP. These samples were incubated at $42^{\circ} \mathrm{C}$ for $40 \mathrm{~min}$. The reaction was terminated by incubation at $99^{\circ} \mathrm{C}$ for $5 \mathrm{~min}$. To compare RT-PCR results from different cell samples, the cDNA encoding $\beta$-actin was adjusted to the same concentration using the PCR MIMIC assay following the procedure provided by the manufacturer (CLONTECH, Palo Alto, CA). To avoid errors of variation between experiments, samples that were to be compared with each other were all extracted from cells on the same day, and were analyzed in the same experiment.

Amplification by PCR. PCR amplification of a targeted gene sequence was carried out using the automated thermocycler RoboCycler 40 (Stratagene). Each 20- $\mu 1$ reaction volume consisted of water, $2 \mu \mathrm{l} 10 \times$ PCR buffer, $0.2 \mu \mathrm{l}$ of $10 \mathrm{mM}$ dNTP mix (Boehringer, Indianapolis, IN), $0.2 \mu \mathrm{l}$ AmpliTaq DNA polymerase (Perkin Elmer Corp.), $2 \mu$ l first-strand cDNA, and 20 pmol of each PCR primer. The reaction mixture was subjected to 30 amplification cycles, each consisting of $96^{\circ} \mathrm{C}$ for $1 \mathrm{~min}$, a predetermined annealing temperature for $30 \mathrm{~s}$, and finally $72^{\circ} \mathrm{C}$ for $1 \mathrm{~min}$. The PCR products were electrophoresed in $2 \%$ agarose gels. To assess the amount of each amplified product, the DNA was stained with ethidium bromide and photographed with a Polaroid type 55 film (Polaroid, Cambridge, MA). The density of each band in the negative of the film was measured by an UltroScan XL (Pharmacia LKB Biotechnology Inc.). All the densitometry measurements observed in this paper fell in a linear relationship with the amount of DNA. Oligonucleotides were synthesized with an Applied Biosystem 394 DNA/RNA synthesizer (Perkin-Elmer Corp.) according to standard procedures. DNA was purified using solid-phase extraction cartridges. The sequences of the PCR primers are shown in Table I. The sequences follow those previously published by other investigators (13-20).

MIMIC PCR assay for c-fos. MIMIC PCR internal standards for both human $\beta$-actin and c-fos were provided by the pQB3 plasmid (Dr. D. Shire, Sanofi, Labége, France; 21). This plasmid was transformed into TOP10F' E. coli (Invitrogen, San Diego, CA). The transformed bacteria were cultured in Luria Broth with $100 \mu \mathrm{g} / \mathrm{ml}$ of carbenicillin. Plasmid DNA was extracted by the QIAprep Spin Miniprep Kit (QIAGEN Inc.), and was linearized using two sequential additions of $40 \mathrm{U}$ of EcoRI (Stratagene Inc.) per $4 \mu \mathrm{g}$ of plasmid. Serial tenfold and twofold dilutions of this preparation were made. The method of this $\beta$-actin and c-fos MIMIC assay was based on the Clontech MIMIC protocol. The PCR primers were based on the sequences of the internal standards in the pQB3, and were as follows: $\beta$-actin sense, 5'-GGGTCAGAAGGATTCCTATG-3'; $\beta$-actin antisense, 5'-GGTCTCAAACATGATCTGGG-3'; c-fos sense, 5'-GAGCTGACTGATACACTCCA-3'; and c-fos antisense, 5'-GCTCTTGACAGGTTCCACTG-3'. Each PCR reaction was $10 \mu \mathrm{l}$ in volume and contained $1 \mu \mathrm{l}$ of cDNA to be assayed, $1 \mu \mathrm{l}$ of diluted standard, $1 \mu \mathrm{l}$ of $10 \times$ PCR Buffer (Perkin-Elmer Corp.), $100 \mu \mathrm{M}$ each of dNTPs, $1 \mu \mathrm{M}$ each of sense and antisense primers, and $1 \mathrm{U}$ of AmpliTaq Gold (Perkin-Elmer Corp.). Each PCR reaction consisted of $94^{\circ} \mathrm{C}$ 


\begin{tabular}{|c|c|c|c|}
\hline $\begin{array}{l}\text { mRNA } \\
\text { species }\end{array}$ & 5' primer & 3' primer & $\begin{array}{l}\text { bp of PCR } \\
\text { products }\end{array}$ \\
\hline IL-1 $\alpha$ & 5'-GTCTCTGAATCAGAAATCCTTCTATC-3' & 5'-CATGTCAAATTTCACTGCTTCATCC-3' & 420 \\
\hline IL-1 $\beta$ & 5'-GAGCTCGCCAGTGAAATGATGGC-3' & 5'-GCCCTGAGTGTCGTTTTTTCGAAC-3' & 386 \\
\hline IL-2 & 5'-ATGTACAGGATGCAACTCCTGTCTT-3' & 5'-GTTAGTGTTGAGATGATGCTTTGAC-3' & 458 \\
\hline IL-4 & 5'-ATGGGTCTCACCTCCCAACTGCT-3' & 5'-CGAACACTTTGAATATTTCTCTCTCAT-3' & 456 \\
\hline IL-5 & 5'-GCTTCTGCATTTGAGTTTGCTAGCT-3' & 5'-TGGCCGTCAATGTATTTCTTTATTAAG-3' & 293 \\
\hline IL-6 & 5'-ATGAACTCCTTCTCCACAAGCGC-3' & 5'-GAAGAGCCCTCAGGCTGGACTG-3' & 628 \\
\hline IL-8 & 5'-ATGACTTCCAAGCTGGCCGTGGCT-3' & 5'-TCTCAGCCСТCТTCAAAАACTTCTC-3' & 289 \\
\hline IL-10 & 5'-ACCAAGACCCAGACATCAAGG-3' & 5'-GCCCCAAGCCCAGAGACAAGA-3' & 600 \\
\hline IL-12(P40) & 5'-ATGTCGTAGAATTGGATTGGTATCCG-3' & 5'-GTACTGATTGTCGTCAGCCACCAGC-3' & 358 \\
\hline TGF- $\beta 1$ & 5'-GCCCTGGACACCAACTATTGCT-3' & 5'-AGGCTCCAAATGTAGGGCAGG-3' & 303 \\
\hline $\mathrm{TNF}-\alpha$ & 5'-CGGGACGTGGAGCTGGCCGAGGAG-3' & 5'-CACCAGCTGGTTATCTCTCAGCTC-3' & 355 \\
\hline IFN- $\gamma$ & 5'-ATGAAATATACAAGTTATATCTTGGCTTT-3' & 5'-GATGCTCTTCGACCTCGAAACAGCAT-3' & 501 \\
\hline GM-CSF & 5'-ACACTGCTGAGATGAATGAAACAGTAG-3' & 5'-TGGACTGGCTCCCAGCAGTCAAAGGGATG-3' & 286 \\
\hline MCP-1 & 5'-TCTGTGCCTGCTGCTCATAGC-3' & 5'-GGGTAGAACTGTGGTTCAAGAGG-3' & 510 \\
\hline CD14 & 5'-ACTCCCTCAATCTGTCGTTCGCTG-3' & 5'-CTGAAGCCAAGGCAGTTTGAGTCC-3' & 338 \\
\hline LIF & 5'-AGATCAGGAGCCAACTGGCA-3' & 5'-ACCCAACTCCTGAGATCCCT-3' & 517 \\
\hline Integrin $\beta 1$ & 5'-GCGAAGGCATCCCTGAAAGT-3' & 5'-GGACACAGGATCAGGTTGGA-3' & 663 \\
\hline CD44 & 5'-CAGACCTGCCCAATGCCTTTGATGGACC-3' & 5'-CAAAGCCAAGGCCAAGAGGGATGCC-3' & 445 \\
\hline$c-F o s$ & 5'-AGCTATСТССТGAAGAGGAA-3' & 5'-AGGCTCCCAGTCTGCTGCAT-3' & 524 \\
\hline c-Jun & 5'-ATGCCCTCAACGCCTCGTTCC-3' & 5'-CTGGGCAGCGTGTTCTGGCTGT-3' & 352 \\
\hline$\beta$-actin & 5'-AACTGGGACGACATGGAGAA-3' & 5'-ATACCCCTCGTAGATGGGCA-3' & 253 \\
\hline
\end{tabular}

Annealing temperature for all primers was $60^{\circ} \mathrm{C}$, except that for $\mathrm{CD} 14$ which was $56^{\circ} \mathrm{C}$.

for $9 \mathrm{~min}$, followed by 10 cycles each with $30 \mathrm{~s}$ at $94^{\circ} \mathrm{C}, 30 \mathrm{~s}$ at $60^{\circ} \mathrm{C}$, and $45 \mathrm{~s}$ at $72^{\circ} \mathrm{C}$. This reaction was followed by a second amplification of 17 cycles for $\beta$-actin and 20 cycles for c-fos, each cycle consisting of $94^{\circ} \mathrm{C}$ for $30 \mathrm{~s}, 55^{\circ} \mathrm{C}$ for $30 \mathrm{~s}$, and $72^{\circ} \mathrm{C}$ for $45 \mathrm{~s}$. The final extension step was at $72^{\circ} \mathrm{C}$ for $3 \mathrm{~min} .5 \mu \mathrm{l}$ of each PCR product was applied on a $1.5 \%$ agarose gel and visualized by ethidium bromide staining. The size of the PCR fragment derived from the internal standard was $410 \mathrm{bp}$. The sizes of the amplicons for $\beta$-actin and c-fos were 237 and 296 bp, respectively.

Hypersensitive detection of c-fos $P C R$ products using biotinylated $P C R$ probes. PCR products of $\mathrm{c}$-fos and $\beta$-actin were generated by RT-PCR as described in the previous section. Using these PCR products as templates, biotinylated PCR probes were synthesized using BrightStar DECAprime-Biotin Kit following the protocol provided by the manufacturer (Ambion Inc., Austin, TX). PCR products to be tested by these biotinylated probes were electrophoresed in $1.5 \%$ agarose gels. Afterwards, the samples were denatured by incubating the gels in $0.2 \mathrm{~N} \mathrm{NaOH}, 0.6 \mathrm{M} \mathrm{NaCl}$ for $45 \mathrm{~min}$. The $\mathrm{pH}$ was adjusted to neutral by incubating the gels in $0.6 \mathrm{M} \mathrm{NaCl}, 0.24 \mathrm{M}$ Tris- $\mathrm{HCl}$, $\mathrm{pH}$ 7.4. Subsequent procedures and reagents used the NorthernMax Kit (Ambion Inc.). PCR products in each gel were transferred using a downward capillary method to a Zeta-Probe Blotting Membrane (Bio-Rad Laboratories, Hercules, CA). The membrane was baked at $80^{\circ} \mathrm{C}$ for $30 \mathrm{~min}$ in a vacuum oven, and then incubated in prehybridization buffer at $42^{\circ} \mathrm{C}$ for 30 min before transfer into the hybridization buffer. A biotinylated probe was added to the membrane in $10 \mathrm{ml}$ of hybridization buffer. Detection of hybridized biotinylated probes on the membrane used the reagents and the procedure of the BrightStar BioDetect Kit (Ambion Inc.). The chemiluminescence was detected by exposure for $1 \mathrm{~h}$ to a X-OMAT AR film (Eastman Kodak Co., Rochester, NY)

Extraction of nuclear proteins, and testing for transcription factors by the electrophoretic mobility shift assay (EMSA). To extract nuclear proteins, $1 \times 10^{7}$ cells were washed in ice-cold PBS, resuspended in $0.4 \mathrm{ml}$ of $10 \mathrm{mM} \mathrm{KCl}, 1 \mathrm{mM}$ DTT, $0.1 \mathrm{mM}$ EGTA, $0.1 \mathrm{mM}$ EDTA,
$0.1 \mathrm{mM}$ aminoethylbenzenesulfonyl fluoride, and $10 \mathrm{mM}$ Hepes, $\mathrm{pH} 7.9$, and incubated on ice for $15 \mathrm{~min} .25 \mu \mathrm{l}$ of a $10 \%$ Nonidet P-40 in water were added with gentle mixing to lyse the cell membrane. The intact nuclei were pelleted by centrifugation for $5 \mathrm{~min}$ at 1,000 $\mathrm{rpm}$ and resuspended in $75 \mu \mathrm{l}$ of $400 \mathrm{mM} \mathrm{NaCl}, 1.0 \mathrm{mM}$ EGTA, $1.0 \mathrm{mM}$ EDTA, $1 \mathrm{mM}$ DTT, $33 \mu \mathrm{g} / \mathrm{ml}$ aprotinin, $10 \mu \mathrm{g} / \mathrm{ml}$ leupeptin, $10 \mu \mathrm{g} / \mathrm{ml}$ trans-Epoxysuccinyl-L-leucylamido(4-guanidino) butane, $10 \mu \mathrm{g} / \mathrm{ml}$ pepstatin A, $2 \mathrm{mM}$ AEBSF, and $20 \mathrm{mM}$ Hepes, pH 7.9. Reagents were purchased from Sigma Chemical Co. (St. Louis, MO). The sample was incubated at $4^{\circ} \mathrm{C}$ in constant rotation for $30 \mathrm{~min}$ to lyse the nuclear membrane. Debris was removed by a 7 -min centrifugation at $14,000 \mathrm{rpm}$ at $4^{\circ} \mathrm{C}$. Protein concentration in the supernatant was determined using the Protein Assay Kit (Bio-Rad Laboratories).

To test for the presence of a particular transcription factor, $100 \mathrm{ng}$ of a double-stranded oligonucleotide containing the consensus sequence for binding to that transcription factor was isotopically labeled using $\mathrm{T} 4$ polynucleotide kinase and $50 \mathrm{Ci}$ of $\left[{ }^{32} \mathrm{P}\right] \mathrm{dATP}$ with a specific activity of $\sim 10^{8} \mathrm{cpm} / \mu \mathrm{g}$ (both from Amersham Corp.) in 1 $\mathrm{mM}$ EDTA, $50 \mathrm{mM} \mathrm{NaCl}$, and $10 \mathrm{mM}$ Tris- $\mathrm{HCl}$, $\mathrm{pH}$ 8.0. Unincorporated $\left[{ }^{32} \mathrm{P}\right] \mathrm{dATP}$ was removed by centrifugation through a STE select-D G25 column ( 5 prime $\rightarrow 3$ prime, Boulder, CO). The amount of incorporated isotope was assessed by scintillation counting. The double-stranded oligonucleotides were purchased from Santa Cruz Biotechnology. Their sequences were as follows: SRE, 5' GGATGTCCATATTAGGACATCT 3'; NF B, 5' AGTTGAGGGGACTTTCCCAGGC 3'; CREB, 5' AGAGATTGCCTGACGTCAGAGAGCTAG 3'; Sis-inducible enhancer (SIE), GTGCATTTCCCGAAATCTTGTCTACA 3'; AP-1, 5' CGCTTGATGACTCAGCCGGAA 3'; mutant AP-1, 5' CGCTTGATGACTTGGCCGGAA 3'.

For each EMSA sample, $8 \mu \mathrm{g}$ of nuclear protein was added into a $15-\mu \mathrm{l}$ reaction mixture containing $50 \mathrm{mM} \mathrm{KCl}, 10 \%$ glycerol, $0.5 \mathrm{mM}$ DTT, $0.1 \mathrm{mM}$ EDTA, $4 \mu \mathrm{g}$ poly(dI-dC), $1 \mu \mathrm{g}$ herring sperm DNA (Promega Corp.), and $20 \mathrm{mM}$ Hepes, pH 7.9, with 100,000 cpm of a labeled oligonucleotide. The sample was incubated at $0^{\circ} \mathrm{C}$ for $20 \mathrm{~min}$. For each competitive assay, nuclear protein was first incubated with 
100-fold molar excess of unlabeled competitor oligonucleotide at $0^{\circ} \mathrm{C}$ for $15 \mathrm{~min}$ before addition of the radioactive oligonucleotide. For each supershift assay, $1 \mu \mathrm{l}$ of an antibody preparation was added to the nuclear protein and incubated at $0^{\circ} \mathrm{C}$ for $30 \mathrm{~min}$ before, adding the labeled oligonucleotide. Rabbit antibodies specific for human c-fos, fosB, c-jun, junB, and junD were purchased from Santa Cruz Biotechnology. EMSA samples were electrophoresed in $4 \%$ polyacrylamide gels in $\mathrm{pH} 8.3$ Tris-borate-EDTA buffer at $150 \mathrm{~V}$ for $2 \mathrm{~h}$. After drying, the gels were exposed for $24 \mathrm{~h}$ at $-80^{\circ} \mathrm{C}$ to x-ray films (Eastman Kodak Co.).

ELISA for IL-2, IL-6, IL-8 and MCP-1. ELISA for IL-2, IL-6, IL-8, and MCP-1 with minimum sensitivity of $9,2,15$, and $20 \mathrm{pg} / \mathrm{ml}$, respectively, were carried out with Cytoscreen Immunoassay Kits purchased from BioSource International (Camarillo, CA). Supernatants of cell cultures either undiluted or diluted with culture media were added to ELISA wells coated with antibodies against the corresponding cytokine or chemokine. After washing, biotin-conjugated antibody preparation directed against the same molecule was added. The amount of reactive antibody was determined by Streptavidin-HRP and a chromogen provided by the commercial test kits. Standard amounts of molecules were assayed in parallel for comparison. Samples were assayed in duplicate.

\section{Results}

Generation of transfectants in the Hela cell line. From the cDNA of the $\mathrm{B} * 2705$, a gene was constructed that lacked the sixth and seventh exons encoding the cytoplasmic tail. This mutant HLA-B27 gene was cloned into the eukaryotic expression vector RSV5.neo. RSV5.neo carrying the cDNA of the parent $\mathrm{B} * 2705$, the mutant HLA-B27, or the HLA-A1 were separately transfected into the Hela cell line. These are designated respectively as the B27-Hela, the mutant B27-Hela, and the A1-Hela. To verify that the truncated B27 gene encoded an HLA class I heavy chain of smaller molecular weight, B27Hela and mutant B27-Hela cells were isotopically labeled and immunoprecipitated with the ME1 antibody. The HLA-B27 heavy chain of the B27-Hela cells was $45 \mathrm{kD}$. The heavy chain of the mutant B27-Hela cells was $43 \mathrm{kD}$, in agreement with the sizes of the respective cDNA. B27-Hela and mutant B27-Hela were tested in flow cytometry with the anti-HLA-B27 monoclonal antibody ME1, and the A1-Hela with the anti-HLA-A1 monoclonal antibody GS142.2. The results of these experiments showed that the levels of expression of these transfected genes were within the same logarithmic range of immunofluorescence values. The parent Hela was unreactive with either antibody (Fig. 1, right). The panel of cell lines was also tested with the W6/32 antibody, which does not discriminate HLA class I alleles. The mean fluorescence intensities of Hela, A1Hela, B27-Hela, and mutant B27-Hela were 12.2, 22.4, 29.5, and 48.4, respectively, indicating that the B27-Hela was not the one expressing the highest number of surface molecules encoded by the transfected gene (Fig. 1, left).

Expression of transfected genes did not change the number of cell-associated Salmonella. The number of cell-associated Salmonella were enumerated at various time points after adding Salmonella. No bacteria were recovered with the noninvasive mutant SB111. With the wild-type strain SL1344, significant numbers were recovered $3 \mathrm{~h}$ after adding the bacteria. However, there were no statistically significant differences among the various cell lines. For this time point, a total of three separate triplicate experiments was carried out (Fig. 2). Although a lack of ability of Salmonella to replicate in Hela cells has already been reported by other investigators (22), we still tested our samples $24 \mathrm{~h}$ after adding the bacteria. Indeed, less than 10 bacteria were recovered from each $2 \times 10^{5}$ cell sample. In one experiment, samples were also tested $48 \mathrm{~h}$ after adding the bacteria. No colony-forming Salmonella were observed.

Salmonella invasion into B27-Hela cells induced expression of c-fos. To test for the levels of c-fos mRNA, B27-Hela as well as the parent Hela cells were subjected to invasion by wild-type Salmonella typhimurium as well as mock invasion. RNA was extracted at the following time intervals: $1 \mathrm{~min}, 30$ min, $60 \mathrm{~min}$, and overnight. RT-PCR was carried out. The densitometry readings of the ethidium bromide-stained PCR products of c-fos and $c$-jun are shown in Fig. $3 a$.

For the B27-Hela cells, there was an increase in RT-PCR results of the c-fos $30 \mathrm{~min}$ after adding the Salmonella. The increase was even more at $60 \mathrm{~min}$, but subsided to baseline level the next day. This extent of the increase was not observed with mock invasion or with the parent Hela cells. No increase was observed with the $c$-jun RT-PCR products irrespective of the HLA-B27.

To ensure the specificity of the PCR procedure and the reproducibility of the results, PCR products generated in a sepa-
W6/32
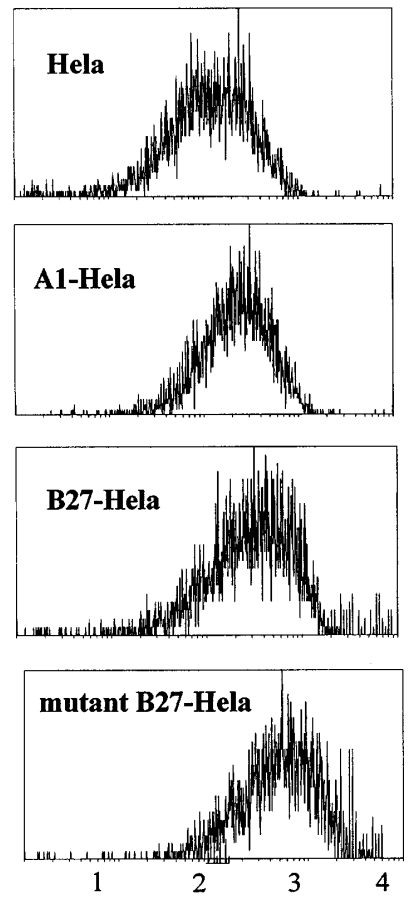
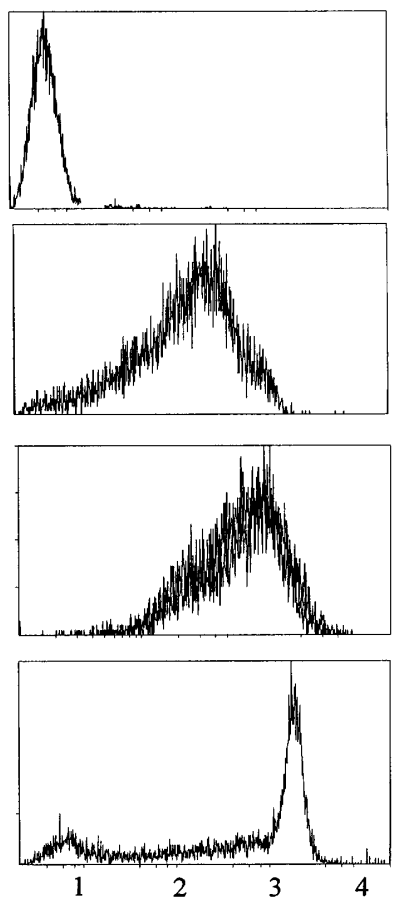

\section{ME1 or GS142.2}

Figure 1. Antibody reactivity of the parent Hela cell line and its transfectants. Hela cells were separately transfected with the HLA-A1 and the HLA-B27 genes as well as with the mutant HLA-B27 gene. All four cell lines were tested with the W6/32 antibody (left). A1-Hela was tested with the GS142.2 antibody, B27-Hela, and mutant B27-Hela with the ME1 antibody (right). Parent Hela cells were tested separately with each of these antibodies. Results with the parent Hela cells were negative with either antibody. Only that with ME1 is shown here. Each cell line on the right corresponds to that on the left. $\mathrm{y}$-axis shows the numbers of cells. $\mathrm{x}$-axis shows immunofluorescence values in logarithms of ten. 


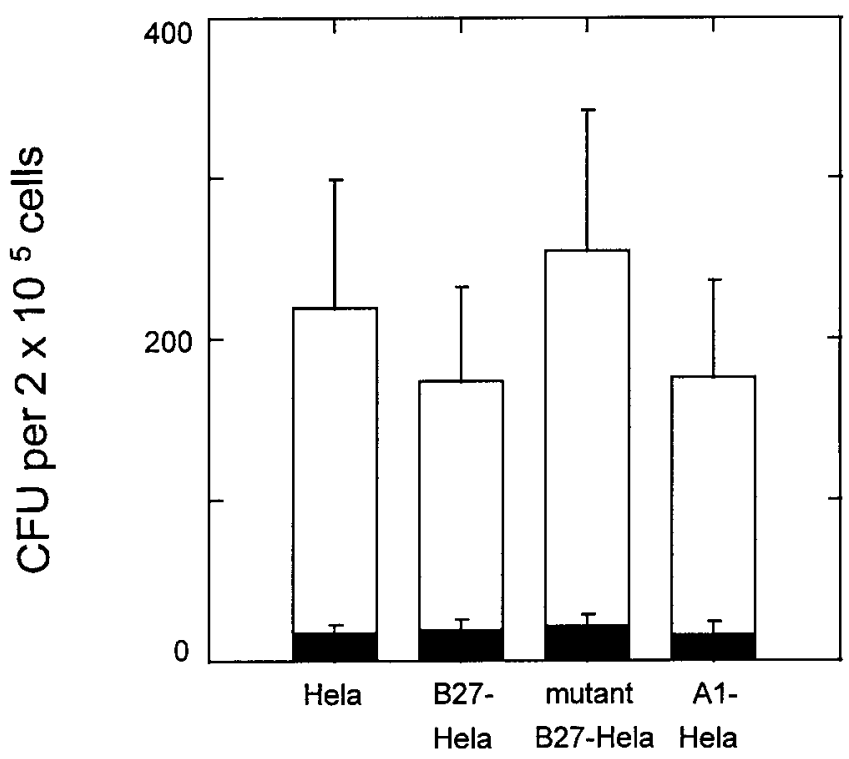

Figure 2. Number of colony-forming Salmonella typhimurium retrieved from cells $3 \mathrm{~h}$ after adding the bacteria. Salmonella typhimurium SL1344 ( $\square$ ) or SB111 (ם) were added to cells at a ratio of 25:1. Cells were washed free of bacteria $1 \mathrm{~h}$ afterwards, and lysed with Triton X-100 $3 \mathrm{~h}$ after adding the bacteria. A total of three separate triplicate experiments were carried out. Results shown here are the mean values and standard errors of all nine separate measurements. There is no significant difference among the cell lines.

rate experiment and obtained from cells $1 \mathrm{~h}$ after adding Salmonella were tested in a hybridization assay with a biotinlabeled c-fos probe. Because of the heightened sensitivity, a much stronger positive result was observed in the B27-Hela cells that were incubated with Salmonella. In spite of the increased intensity, no other positive bands were observed in the same lane. Also validating the specificity, no positive band was observed with the mock invasion sample, or with any of the parent Hela cell samples. Uniform reactivity with the $\beta$-actin probe served as a control (Fig. $3 b$ ).

In the next experiment, we added A1-Hela as a control for B27-Hela, noninvasive mutant as a control for the wild-type Salmonella, and finally precision in RT-PCR analysis by using a plasmid with internal standards for both $\beta$-actin and c-fos. Based on the time sequence shown in Fig. $3 a$, cells were incubated for $1 \mathrm{~h}$ with bacteria before extraction of RNA. For each sample, the result with the c-fos was expressed as a ratio of the result of the $\beta$-actin derived from the same sample. $C$-fos expression with the wild-type Salmonella using the B27-Hela cells was at least four times those of other samples (Fig. 3c).

Salmonella invasion into B27-Hela cells induced generation of transcription factors for the c-fos promoter. Within the c-fos promoter, there are at least three distinct cis-acting response elements that bind transcription factors: the Sis-inducible enhancer (SIE), the serum response element (SRE), and the cAMP response element (CRE; 23). Oligonucleotides carrying the respective consensus sequences were isotopically labeled. For comparison, we also labeled an oligonucleotide corresponding to the binding sequence of nuclear factor ${ }_{\kappa} \mathrm{B}(\mathrm{NF}-\kappa \mathrm{B})$. EMSA was carried out using nuclear factors extracted from B27-Hela cells. With the SIE and NF-kB oligonucleotides, the bands that could be observed were rather faint irrespective of
Salmonella invasion (Fig. 4, lanes 1-6). With the CREB oligonucleotide, one major band was observed even without Salmonella invasion. This strong CREB band was specific because it was completely inhibited by the presence of excess unlabeled CREB oligonucleotide (Fig. 4, lanes 10-12).

The most remarkable result was observed with the labeled SRE oligonucleotide. In the sample with mock invasion, two bands were observed: a strong upper and a very faint lower band (Fig. 4, lane 7). In the sample incubated with Salmonella, the lower band became much stronger in intensity (Fig. 4, lane 8 ). As a test for specificity, the appearances of both bands were completely inhibited when the samples were incubated in the presence of excess unlabeled SRE oligonucleotide (Fig. 4, lane 9).

In the next experiment, the EMSA with the labeled SRE oligonucleotide was repeated. The results were identical to those of the previous experiment (Fig. 5, lanes 1-3). At the same time, nuclear proteins prepared from the following cell lines were also assayed: parent Hela, mutant B27-Hela, and A-1Hela. With these three cell lines, only the upper band was observed. In none of these cell lines was the lower band induced by Salmonella invasion (Fig. 5, lanes 4-9).

Salmonella invasion into B27-Hela cells also induced a positive EMSA with the AP-1 oligonucleotide. Since the generated c-fos would potentially complex with a member of the c-jun family to become the AP-1 complex transcription factors, EMSA was carried out using such a double-stranded AP-1 oligonucleotide. A positive autoradiography band was observed with the Salmonella-exposed B27-Hela cells (Fig. 6, lane 2). Significantly, the result was negative with mock invasion (Fig. 6 , lane 1). The results were also negative with the parent Hela cells (Fig. 6, lanes 3 and 4), or the mutant B27-Hela cells (Fig. 6, lanes 5 and 6), or the A1-Hela cells (Fig. 6, lanes 7 and 8) irrespective of Salmonella invasion. B27-Hela cells were also tested with the noninvasive Salmonella typhimurium mutant SB111 as well as this Salmonella mutant carrying the Yersinia invasin gene. Results were negative and are not shown in the figure.

To test the reproducibility of this AP-1 experiment, the assay with the B27-Hela cells was repeated. The results were the same (Fig. 7, lanes 1 and 2). In addition, to verify the authenticity of the observation, the appearance of the positive AP-1 band was inhibited when the sample was incubated with an excess of unlabeled AP-1 oligonucleotide (Fig. 7, lane 3). As additional verification, results were negative, with labeled mutant AP-1 oligonucleotide carrying an ineffective sequence (Fig. 7, lanes 9 and 10).

An experiment was also carried out to test which members of the AP-1 transcription families were involved in the positive AP-1 assay using antibodies against the following gene products: $c$-jun, jun $\mathrm{B}$, jun $\mathrm{D}$, c-fos, and $f o s \mathrm{~B}$. With antibodies against products of c-fos and jun $\mathrm{D}$, in addition to the positive band, an additional band of higher molecular weight was observed (Fig. 7, lanes 6 and 7). Supershift was not observed with the other antibodies.

Salmonella invasion induced gene expression of MCP-1 in B27-Hela cells. RNA derived from Hela and B27-Hela cells were tested in RT-PCR with PCR primers designed to detect the following: IL-1 $\alpha$, IL-1 $\beta$, IL-2, IL-4, IL-5, IL-6, IL-8, IL-10, IL-12, TGF- $\beta 1$, TNF $\alpha$, IFN $\gamma$, GM-CSF, CD14, leukemia inhibitory factor, integrin $\beta 1$, and CD44. In both Hela and B27Hela, positive PCR products were observed with TGF- $\beta 1$ and 

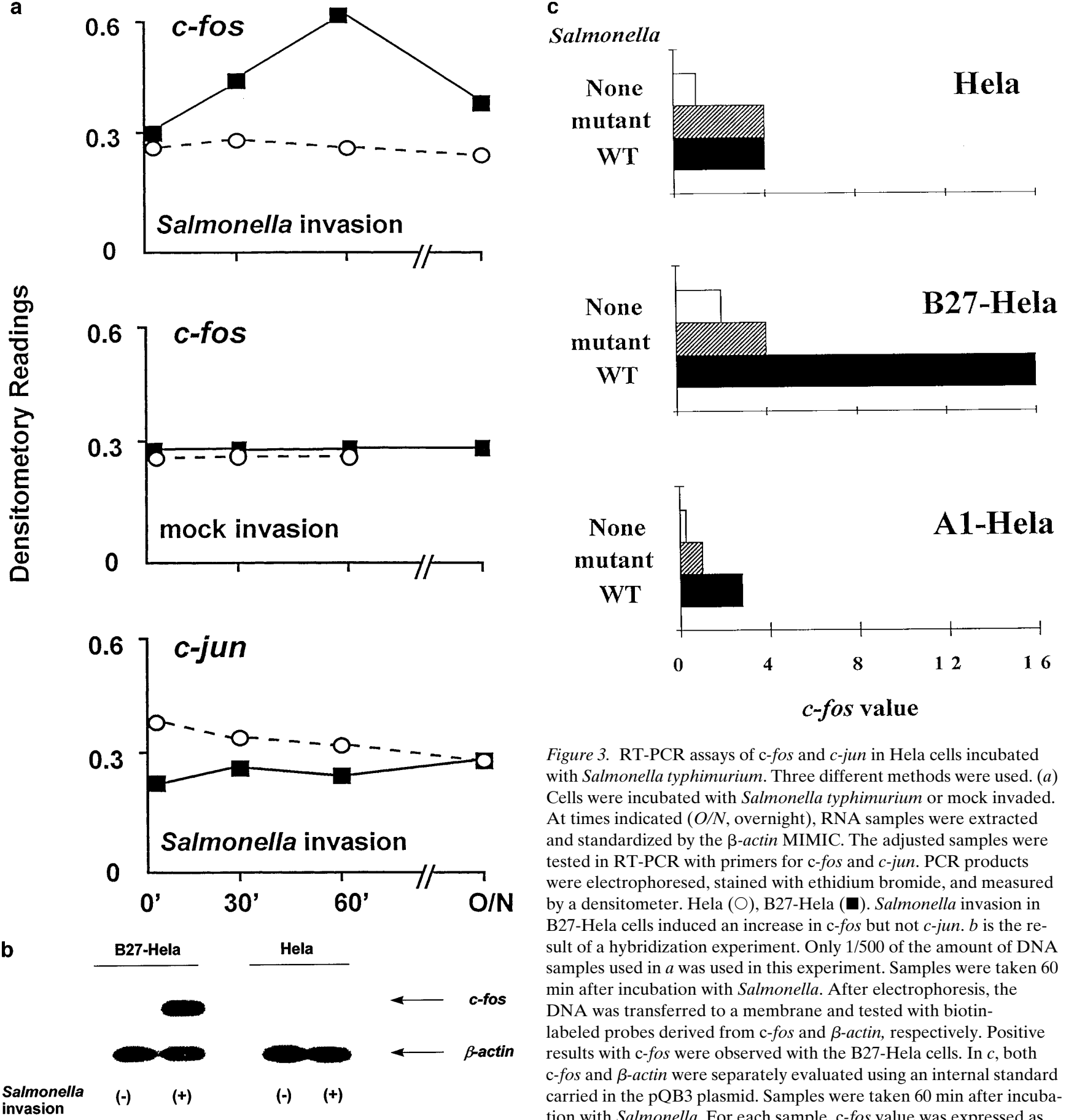

Figure 3. RT-PCR assays of c-fos and c-jun in Hela cells incubated with Salmonella typhimurium. Three different methods were used. (a) Cells were incubated with Salmonella typhimurium or mock invaded. At times indicated $(O / N$, overnight), RNA samples were extracted and standardized by the $\beta$-actin MIMIC. The adjusted samples were tested in RT-PCR with primers for c-fos and c-jun. PCR products were electrophoresed, stained with ethidium bromide, and measured by a densitometer. Hela $(\bigcirc)$, B27-Hela $(\boldsymbol{\square})$. Salmonella invasion in B27-Hela cells induced an increase in c-fos but not $c$-jun. $b$ is the result of a hybridization experiment. Only $1 / 500$ of the amount of DNA samples used in $a$ was used in this experiment. Samples were taken 60 min after incubation with Salmonella. After electrophoresis, the DNA was transferred to a membrane and tested with biotinlabeled probes derived from c-fos and $\beta$-actin, respectively. Positive results with c-fos were observed with the B27-Hela cells. In $c$, both c-fos and $\beta$-actin were separately evaluated using an internal standard carried in the pQB3 plasmid. Samples were taken 60 min after incubation with Salmonella. For each sample, c-fos value was expressed as

the ratio of the corresponding $\beta$-actin value. To the three separate cell lines the following was added: no bacteria in mock invasion (white bars), mutant SB111 (striped bars), and wild-type SL1344 (black bars). The highest value was observed with the wild-type Salmonella using B27-Hela cells.

CD44. However, they were not increased by Salmonella invasion whether the RNA were extracted $30 \mathrm{~min}, 60 \mathrm{~min}$, or overnight after addition of bacteria. No RT-PCR products were observed with the other genes irrespective of the HLA-B27 or Salmonella invasion.

The results with MCP-1 were quite different. Negligible PCR product was observed with samples from the B27-Hela cells before addition of Salmonella. The results became positive 30 and $60 \mathrm{~min}$ after adding the bacteria, returning to baseline value after overnight incubation. The result was completely negative with the parent Hela cells. The experiment was carried out twice with similar results. The results of one of the experiments are shown in Fig. 8.

In separate experiments, supernatants were harvested from 


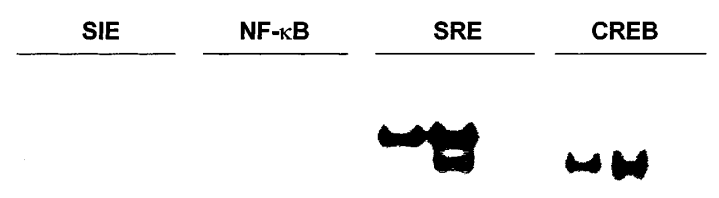

\begin{tabular}{|l|ccc|ccc|ccc|cc|}
\hline $\begin{array}{l}\text { Salmonella } \\
\text { invasion }\end{array}$ & - & + & + & - & + & + & - & + & + & - & + \\
\hline $\begin{array}{l}\text { Unlabeled } \\
\text { competitor }\end{array}$ & - & - & + & - & - & + & - & - & + & - & - \\
\hline Lanes & 1 & 2 & 3 & 4 & 5 & 6 & 7 & 8 & 9 & 10 & 11 \\
\hline
\end{tabular}

Figure 4. EMSA of transcription factors in B27-Hela cells incubated with Salmonella typhimurium. B27-Hela cells were incubated with Salmonella typhimurium or mock-invaded. Nuclear proteins were extracted and tested in EMSA with isotopically labeled doublestranded oligonucleotides carrying consensus sequences for binding to transcription factors as denoted (top). For each transcription factor complex, specificity of the positive result was tested by adding the corresponding unlabeled oligonucleotides as denoted (bottom). Positive result was observed with CREB regardless of Salmonella. For SRE, incubation with Salmonella induced the appearance of an additional band.

individual samples 1,2 , and $3 \mathrm{~d}$ after adding bacteria. There was a progressive increase in ELISA level of MCP-1 (Fig. 9, left). The levels were barely detectable with parent Hela, mutant B27-Hela, and A-1 Hela, whether incubated with Salmonella or simply mock-invaded. As negative controls, ELISA results were negative with the culture supernatant samples using reagents to assay for IL-2, IL-6, and IL-8, irrespective of cell lines or Salmonella. The negative result with IL-8 was different from that reported by another group of investigators (24). However, we did not use the same Hela cell clone or the same Salmonella strain.

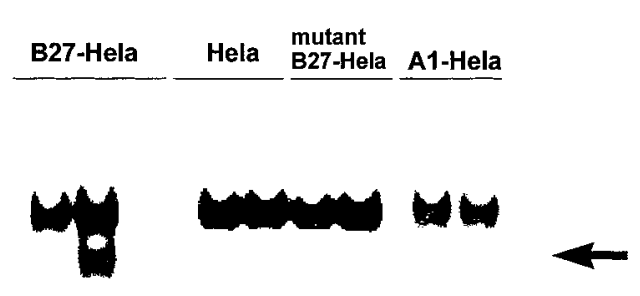

\begin{tabular}{|c|c|c|c|c|c|}
\hline $\begin{array}{l}\text { Salmonella } \\
\text { invasion }\end{array}$ & $-t$ & & $=+$ & -+ & -4 \\
\hline $\begin{array}{l}\text { Unlabeled } \\
\text { Competitor }\end{array}$ & - & + & \multicolumn{3}{|c|}{ - } \\
\hline Lanes & 12 & 3 & 4 & 6 & 8 \\
\hline
\end{tabular}

Figure 5. Effect of Salmonella invasion on the SRE transcription complex in various Hela transfectants. Hela, A1-Hela, B27-Hela, and the mutant B27-Hela were incubated with Salmonella typhimurium. Their nuclear proteins were tested in EMSA with a labeled oligonucleotide carrying the consensus sequence for SRE. One single band was observed with all the cell lines regardless of Salmonella. Incubation of the B27-Hela cells induced the appearance of an additional band. Both bands were inhibited by incubation with unlabeled oligonucleotide.

\begin{tabular}{|c|ccc|cc|cc|cc|}
\hline $\begin{array}{l}\text { Salmonella } \\
\text { invasion }\end{array}$ & - & + & - & + & - & + & - & + \\
\hline Lanes & 1 & 2 & 3 & 4 & 5 & 6 & 7 & 8
\end{tabular}

Figure 6. Effect of Salmonella invasion on the AP-1 transcription complex in various Hela transfectants. Hela, A1-Hela, B27-Hela, and the mutant B27-Hela were incubated with Salmonella typhimurium. Their nuclear proteins were tested in EMSA with a labeled oligonucleotide carrying the consensus sequence for binding to AP-1. Positive result was observed only with the B27-Hela cells and only after incubation with Salmonella.

To validate that the release of MCP-1 was induced by Salmonella, an experiment was carried out in which $10^{5}$ B27-Hela cells were cultured with the following numbers of bacteria: $2 \times$ $10^{5}, 2 \times 10^{6}, 10^{7}, 2 \times 10^{7}$, and $10^{8}$. A progressive increase in MCP-1 concentration was noticed when the bacteria number was increased from $2 \times 10^{6}$ to $10^{8}$ (Fig. 9, right). No MCP-1 was detected using $2 \times 10^{5}$ bacteria. Over this range of bacterial numbers, no MCP-1 was released from parent Hela, mutant B27-Hela, or A1-Hela. No IL-8 was released from B27Hela cells when the same culture supernatants were assayed by ELISA. We also cultured $1 \times 10^{5}$ B27-Hela cells with $2 \times$ $10^{6}, 2 \times 10^{7}$, and $10^{8}$ of the noninvasive mutant Salmonella typhimurium SB111. No MCP-1 was detected in the supernatant by ELISA.
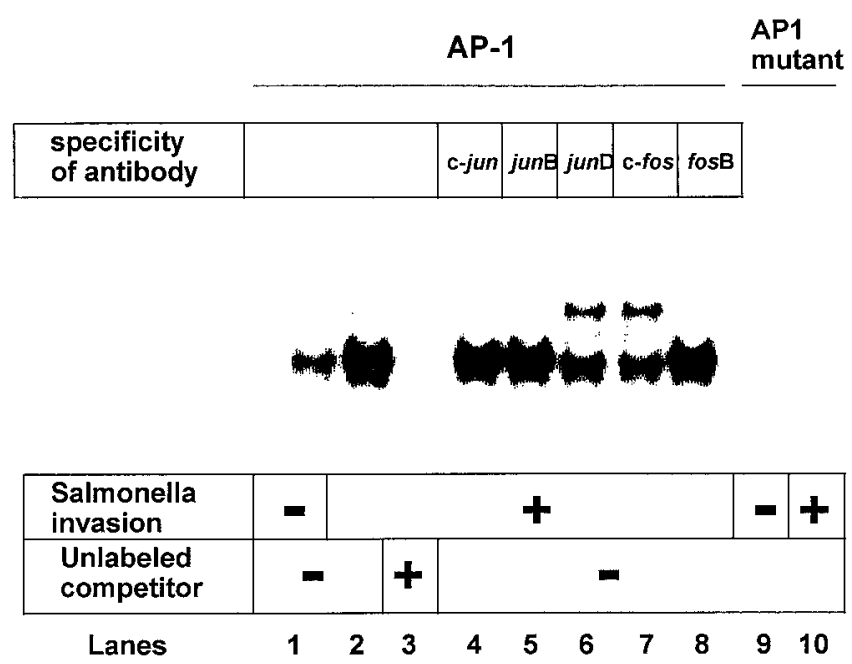

Figure 7. Supershift assay using the AP-1-binding oligonucleotide. B27-Hela cells were incubated with Salmonella typhimurium. Their nuclear proteins were tested in a supershift assay using a labeled oligonucleotide as well as the antibodies shown (top). The bottom denotes whether the cells were incubated with Salmonella, and whether unlabeled oligonucleotide was added in inhibition to test for the specificity. Positive result was observed with the antibodies against c-fos and junD. 


\section{PCR product}
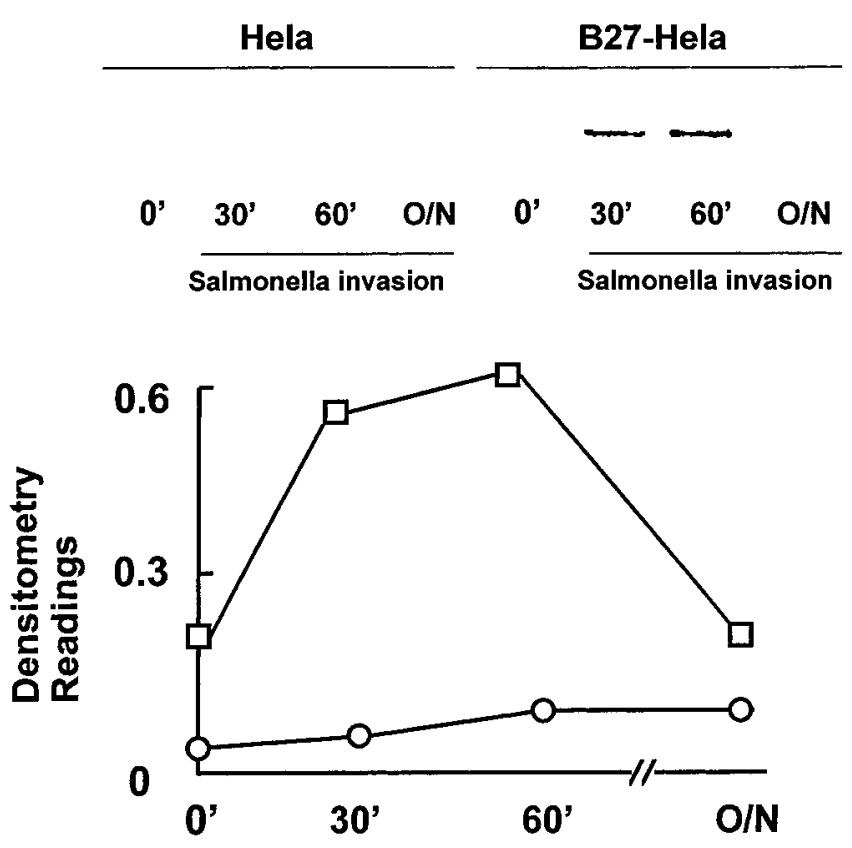

Figure 8. Effect of Salmonella invasion on the RT-PCR results of MCP-1. Hela and B27-Hela cells were incubated with Salmonella typhimurium. RNA samples were extracted at the times indicated after adding the bacteria. $O / N$, overnight. Samples were adjusted by standardization with the $\beta$-actin MIMIC. RT-PCR was carried out using primers for MCP-1. An increase was observed with the B27-Hela cells 30 and $60 \mathrm{~min}$ after adding the bacteria. The top shows the ethidium-stained PCR products. The bottom shows their densitometry readings. B27-Hela $(\square)$; Hela $(\bigcirc)$.

\section{Discussion}

During an infection, the first type of host cell to engage Salmonella is the epithelial cell. Within $24 \mathrm{~h}$ of an in vitro invasion, colon epithelial cells release IL-8, GM-CSF, TNF, and MCP-1 (13). Within minutes of encountering Salmonella, eukaryotic cells such as Hela respond by signal transduction activities
(12). Our goal is to determine if the presence of HLA- B27 can alter the cell response to Salmonella invasion. Many signal transducers are activated during Salmonella invasion, for example, the MAP kinases, inositol phosphate, and the GTPbinding protein CDC42 (25). Although it is not precisely known how they are integrated, their downstream effect is to activate within minutes a few immediate early genes such as c-fos. $C$-fos is particularly appealing to study because it is very susceptible to diverse external extracellular stimuli including growth factors, cytokines, neurotransmitters, ion influxes, phorbol esters, and ultraviolet irradiation (23).

Our first major finding is that Salmonella invasion induced expression of c-fos provided that there was expression of the full-length HLA-B27. Of the three distinct cis elements controlling c-fos, at least two of them need to be engaged to induce gene transcription. In agreement with other investigators, our results show that the CRE factor is constitutively expressed in Hela cells (26). Also in agreement with other investigators, the serum response factor (SRF) is constitutively present, and binds spontaneously to the SRE (27). This SRF is responsible for our single predominant band in the EMSA of the Hela cells and their transfectants. However, the SRF-DNA complex by itself does not induce c-fos transcription; it needs to capture another factor, the ternary complex factor (TCF). The TCF comprises a small family of Ets domain proteins including the ELK-1, SAP-1, and SAP-2. Several individual pathways of the MAPK family, including the ERK, the JNK, and a subgroup corresponding to the p38, can separately lead to activation of the TCF (27). The TCF is probably responsible for the additional SRE EMSA band we observed. Our crucial finding is that this additional SRE band appeared only with the B27-Hela cells, and only when the cells were invaded by Salmonella.

In general, c-fos expression correlates with the onset of global cell differentiation. In this project, we screened a number of genes potentially active in host defense or in arthritis. A positive result was observed with $\mathrm{MCP}-1$. The induction of MCP-1 has been suspected to involve AP-1 since the promoter region carries an AP-1 site (28). In addition, adding antisense oligonucleotides of c-fos and c-jun inhibits MCP-1 gene induction (29).

In summary, the several positive results by different experi-

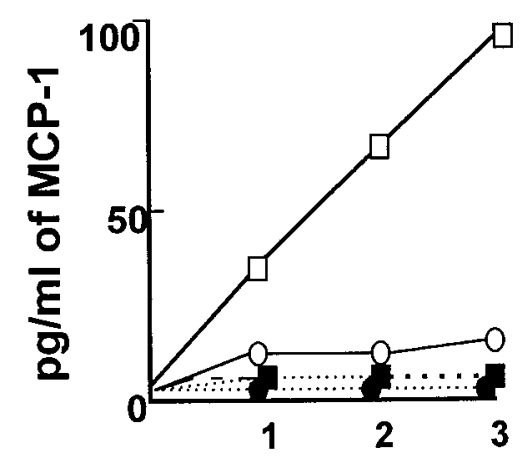

Days of culture

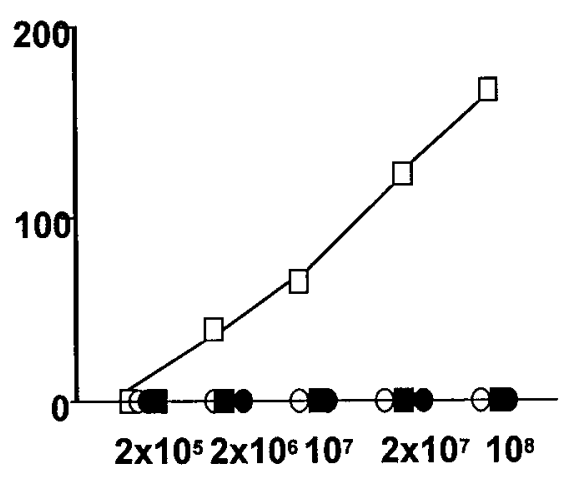

Number of bacteria per well
Figure 9. Effect of Salmonella invasion on release of MCP-1 from Hela cells. Hela and B27-Hela, mutant B27-Hela, and A1-Hela were incubated with Salmonella typhimurium. Culture supernatants were harvested at various days and tested in ELISA. An increase was observed with the B27-Hela cells after incubation with $25 \times$ number of Salmonella bacteria $(l e f t)$. A separate experiment was carried out in which $1 \times$ $10^{5}$ cells were incubated with $2 \times 10^{5}$ $-10^{8}$ Salmonella and MCP-1 in the culture supernatant tested after one day of culture. For clarity, the $\mathrm{x}$-axis is not computed to scale. Results are shown (right). B27-Hela ( $\square$ ); Hela (O); A1- Hela (ם); mutant B27Hela (๑). 
mental approaches lead to the conclusion that expression of HLA-B27 in Hela cells results in a change in their response to Salmonella invasion. A point of caution is that the preferential expression of HLA-B27 by gene transfection is an artificial system involving accessory DNA. To demonstrate relevance to disease, an experimental system is needed in which cells obtained from patients and controls can be tested with minimum manipulation.

How HLA class I molecules participate in Salmonella invasion is not clear. On the Hela cells, HLA class I molecules become clustered together with $\beta 1$ integrin and the hyaluronate receptor in membrane ruffles localized to invading Salmonella (30). Such cross-linking may induce signal transduction. This possibility is supported by reports that ligation of HLA class I molecules on T lymphocytes is associated with tyrosine phosphorylation of signal transducers and influx of intracellular calcium (31). Those $\mathrm{T}$ cell signal transduction events require the participation of the TCR/CD3. Our observation is not a mere extension of those $\mathrm{T}$ lymphocyte experiments because there are no TCR/CD3 on Hela cells.

The surprise in our study is that the activation effect we observed is allele-specific for HLA-B27, even though it does not involve TCR recognition. In fact, multiple HLA class I allelespecific activities other than the engagement of TCR on CD8+ T lymphocytes have already been described. For example, the KIR receptors on natural killer cells are able to distinguish one HLA class I allele from another, and are also peptide-specific within the same HLA class I allele (32). Another example is the increase in insulin affinity when insulin receptors are associated with HLA-A2, but not with other alleles (33). It would appear that MHC class I molecules have evolved to serve multiple masters. Our experiments are unusual in that the cytoplasmic domain of the HLA molecule is also necessary for the positive results even though that domain does not carry any allelic specificity. Allelic specificities are carried in the extracellular $\alpha 1$ and $\alpha 2$ domains. These domains are probably responsible for associating with the neighboring molecules on the cell surface to constitute supramolecular complexes. On the surface of JY B lymphoblastoid cells for example, HLA class $\mathrm{I}$ is part of a supramolecular complex that also includes HLA class II, CD20, and tetraspan molecules (34). Any of these molecules can conceivably associate preferentially with a particular HLA class I allele to become a complex capable of mediating signal transduction. Whether there are fine specificities for the HLA class I alleles or fine specificities in the cytoplasmic domain will require transfection of additional HLA alleles or generation of other mutants such as substituting the cytoplasmic domain of the HLA-B locus by that of the HLA-A locus.

It would be premature to postulate that modification of the epithelial cell response is solely responsible for development of arthritis. Other cell types such as the T lymphocytes, macrophages, and synovial fibroblasts may play more critical roles. In any of these cells, HLA-B27 will promote arthritis if it favors activation of an arthritis-causing cytokine or chemokine such as MCP-1 (35).

\section{Acknowledgments}

We are grateful to Dr. Brett Finlay (University of British Columbia) for the strains of Salmonella typhimurium, and to Dr. Peng Fan Thim for advice.
This project was supported by a grant from the Nora Eccles Treadwell Foundation and from the United States Department of Agriculture Competitive Grants Program/USDA 94-37201-1066.

\section{References}

1. Jalkanen, S., A.A. Lindberg, O. Mäki-Ekola, R. von Essen, R. Lahesmaa-Rantala, H. Isomäki, R. Saario, W.J. Arnold, and A. Toivanen. 1990. Salmonella lipopolysaccharide in synovial cells from patients with reactive arthritis. Lancet. $335: 685-688$.

2. Morris, R., A.L. Metzger, R. Bluestone, and P.I. Terasaki. 1974. HL-A w27: a clue to the diagnosis and pathogenesis of Reiter's syndrome. $N$. Engl. J. Med. 289:554-556.

3. Rubin, L., C.I. Amos, J.A. Wade, J.R. Martin, S.J. Bale, A.H. Little, D.D. Gladman, G.E. Bonney, J.D. Rubenstein, and K.A. Siminovitch. 1994. Investigating the genetic basis for ankylosing spondylitis: linkage studies with the major histocompatibility complex region. Arthritis Rheum. 37:1212-1220.

4. Hammer, R.E., S.D. Maika, J.A. Richardson, J.-P. Tang, and J.D. Taurog. 1990. Spontaneous inflammatory disease in transgenic rats expressing HLA-B27 and human B2m: an animal model of HLA-B27-associated human disorders. Cell. 63:1099-1112.

5. Hermann, E., D.T.Y. Yu, K.-H. Meyer zum Büschenfelde, and B. Fleischer. 1993. HLA-B27-restricted C8+ T cells derived from the synovial fluids of patients with reactive arthritis and ankylosing spondylitis. Lancet. 342:646-650.

6. Kapasi, K., and R.D. Inman. 1992. HLA-B27 expression modulates gramnegative bacterial invasion into transfected L cells. J. Immunol. 148:3554-3559.

7. Laitio, P., M. Virtala, M. Salmi, L.J. Pelliniemi, D.T.Y. Yu, and K. Granfors. 1997. HLA-B27 modulates intracellular survival of Salmonella enteritidis in human monocytic cells. Eur. J. Immunol. 27:1331-1338.

8. Huppertz, H.-I., and J. Heesemann. 1996. The influence of HLA-B27 and interferon- on the invasion and persistence of yersinia in primary human fibroblasts. Med. Microbiol. Immunol. 185:163-170.

9. Cahill, M.A., R. Jacknecht, and A. Nordheim. 1996. Signaling pathways: jack of all cascades. Curr. Biol. 6:16-19.

10. Westman, P., M. Leirisalo-Repo, J. Partanen, and S. Koskimies. 1996. A comparative study of HLA genes in HLA-B27 ankylosing spondylitis and HLA-B27 peripheral arthritis. Arthritis Rheum. 39:943-949.

11. Huang, F., A. Yamaguchi, N. Tsuchiya, T. Ikawa, N. Tamura, M. Virtala, K. Granfors, P. Yasaei, and D.T.Y. Yu. 1997. Bacterial invasion induces alternative splicing of HLA-B27. Arthritis Rheum. 40:694-703.

12. Rosenshine, I., S. Ruschkowski, V. Foubister, and B. Finlay. 1994. Salmonella tyhimurium invasion of epithelial cells: role of induced host cell tyrosine protein phosphorylation. Infect. Immun. 62:4969-4974.

13. Jung, H.C., L. Eckmann, S.-K. Yang, A. Panja, J. Fierer, E. MorzckaWroblewska, and M.F. Kagnoff. 1995. A distinct array of proinflammatory cytokines is expressed in human colon epithelial cells in response to bacterial invasion. J. Clin. Invest. 95:55-65.

14. Geng, Y., E. Gulbins, A. Altman, and M. Lotz. 1994. Monocyte deactivation by interleukin 10 via inhibition of tyrosine kinase activity and the Ras signaling pathway. Proc. Natl. Acad. Sci. USA. 91:8602-8606.

15. Lum, L.G., I.D. Joshi, M.R. Smith, V. Ratanatharanthorn, S.C. Galoforo, C. Karanes, J.P. Uberti, and L.L. Sensenbrenner. 1994. Constitutive and mitogen-stimulated cytokine mRNA expression by peripheral blood mononuclear cells from most autologous and allogeneic bone marrow transplant recipients is intact. Bone Marrow Transplant. 13:187-195.

16. Houssiau, F., L. Schandenè, M. Stevens, C. Cambiaso, M. Goldman, J. Van Scnick, and J.-C. Renauld. 1995. A cascade of cytokines is responsible for IL-9 expression in human T cells. J. Immunol. 154:2624-2630.

17. Bost, K.L., S.C. Bieligk, and B.M. Jaffe. 1995. Lymphokine mRNA expression by transplantable murine B lymphocytic malignancies. Tumor-derived IL-10 as a possible mechanism for modulating the anti-tumor response. J. Immunol. 154:718-729.

18. James-Yarish, M., W.G. Bradley, P.J. Emmanuel, R.A. Good, and N.K. Day. 1994. Detection of cell specific cluster determinant expression by reverse transcriptase polymerase chain reaction. J. Immunol. Methods. 169:73-82.

19. Dall, P., K.-H. Heider, H.-P. Sinn, P. Skroch-Angel, G. Adolf, M. Kaufmann, P. Herrlich, and H. Ponta. 1995. Comparison of immunohistochemistry and RT-PCR for detection of CD44v-expression, a new prognostic factor in human breast cancer. Int. J. Cancer. 60:471-477.

20. Ehrhard, P.B., P. Erb, U. Graumann, B. Schmutz, and U. Otten. 1994 Expression of functional trk tyrosine kinase receptors after T cell activation. $J$. Immunol. 152:2705-2709.

21. Shire, D., and the Editorial staff of E.C.N. 1993. An invitation to an open exchange of reagents and information useful for the measurement of cytokine mRNA levels by PCR. Eur. Cytokine Netw. 4:161-162.

22. Sansonetti, P.J., A. Ryter, P. Clerc, A.T. Maurelli, and J. Mounier. 1986. Multiplication of Shigella flexneri within HeLa cells: lysis of the phagocytic vacuole and plasmid-mediated contact hemolysis. Infect. Immun. 51:461-469.

23. Cavigelli, M., F. Dolfi, F.-X. Claret, and M. Karin. 1995. Induction of c-fos expression through JNK-mediated TCF/Elk-1 phosphorylation. EMBO (Eur. Mol. Biol. Organ.) J. 14:5957-5964. 
24. Eckmann, L., M.F. Kagnoff, and J. Fierer. 1993. Epithelial cells secrete the chemokine interleukin-8 in response to bacterial entry. Infect. Immun. 61: 4569-4574.

25. Chen, L.-M., S. Hobbie, and J.E. Galan. 1996. Requirement of CDC42 for Salmonella-induced cytoskeletal and nuclear responses. Science. 274:21152118.

26. Feurstein, N., D. Huang, S.H. Hinrichs, D.J. Orten, N. Aiyar, and M.B. Prystowsky. 1995. Regulation of cAMP-responsive enhancer binding proteins during cell cycle progression in T lymphocytes stimulated by IL-2. J. Immunol. 154:68-79.

27. Treisman, R. 1994. Ternary complex factors: growth factor regulated transcriptional activators. Curr. Opin. Genet. Dev. 4:96-101.

28. Ueda, A., O. Kenji, S. Ohno, A. Shirai, T. Igarashi, K. Matsunaga, J. Fukushima, S. Kawamoto, Y. Ishigatsubo, and T. Okubo. 1994. NF-кB and Sp1 regulate transcription of the human monocyte chemoattractant protein-1 gene. J. Immunol. 153:2052-2063.

29. Hanazawa, S., A. Takeshita, S. Amano, T. Semba, T. Nirazuka, H. Katoh, and S. Kitano. 1993. Tumour necrosis factor- $\alpha$ induces expression of monocyte-chemoattractant JE via fos and jun genes in clonal osteoblastic MC3. Proc. Natl. Acad. Sci. USA. 84:1351-1355.
30. Portillo, F.G., M.G. Pucciarelli, W.A. Jefferies, and B.B. Finlay. 1994. Salmonella typhimurium induces selective aggregation and internalization of host cell surface proteins during invasion of epithelial cells. J. Cell Sci. 107: 2005-2020.

31. Bregenholt, S., M. Röpke, S. Søren, and M.H. Claesson. 1996. Ligation of MHC molecules on peripheral blood T lymphocytes induces new phenotypes and functions. J. Immunol. 157:993-999.

32. Peruzzi, M., K. Parker, E. Long, and M. Malnati. 1996. Peptide sequence requirements for the recognition of HLA-B*2705 by specific natural killer cells. J. Immunol. 157:3350-3356.

33. Kittur, D., Y. Shimizu, R. DeMars, and M. Edidin. 1987. Insulin binding to human B lymphoblasts is a function of HLA haplotype. Proc. Natl. Acad. Sci. USA. 84: 1351-1355.

34. Szöllösi, J., V. Horejsi, L. Bene, P. Angelisová, and S. Damjanovich. 1996. Supramolecular complexes of MHC class I, MHC class II, CD20, and tetraspan molecules (CD53, CD81, and CD82) at the surface of a B cell line JY.J. Immunol. 157:2939-2946.

35. Gong, J.-H., L.G. Ratkay, J.D. Waterfield, and I. Clark-Lewis. 1997. An antagonist of monocyte-chemoattractant protein 1 (MCP-1) inhibits arthritis in the MRL-lpr mouse model. J. Exp. Med. 186:131-137.1. 